\title{
Characteristics of long-range scintillation data over maritime coastal areas
}

\author{
Arie N. de Jong ${ }^{\mathrm{a}}$, Piet B.W. Schwering ${ }^{\mathrm{a}}$ \\ Willem H. Gunter ${ }^{\mathrm{b}}$, George Vrahimis ${ }^{\mathrm{b}}$, Faith J. October ${ }^{\mathrm{b}}$ \\ ${ }^{a}$ TNO, PO Box 96864, The Hague, The Netherlands \\ ${ }^{\mathrm{b}}$ Institute for Maritime Technology (IMT), Simon's Town 7995, South Africa
}

\begin{abstract}
The knowledge on scintillation, caused by atmospheric turbulence, is of vital importance for the performance prediction of threat detection systems and for the development of associated detection algorithms. Additionally, scintillation data may support the knowledge on turbulence characteristics. Along these ideas, data have been analysed, collected during the FATMOSE trials, carried out over the False Bay (South Africa) over a range of $15.7 \mathrm{~km}$ from November 2009 until October 2010. The collected data include long-range scintillation measurements, taken with the MSRT radiometer and a modulated source and with a high resolution imager and static sources. In addition a standard scintillometer was used over a short range, $1.8 \mathrm{~km}$ parallel path and a mid-path sonic anemometer for direct measurement of windspeed and air temperature fluctuations. Indirectly, information on turbulence parameters is predicted from the weather data, collected at the mid-path station, by using our TARMOS code for the marine boundary layer. Details on the set-up and the method of analysis are given, including some relevant examples. Scintillation spectra between 0.1 and $100 \mathrm{~Hz}$ are shown for investigation of the validity of Kolmogorov's theory of turbulence. In addition, signal (irradiance) statistics are shown for testing the log-normality of their characteristics. In relation to this, attention is spent on the subject of saturation of scintillation, which may occur in conditions of strong turbulence, combined with small apertures and long ranges. Output from the various sensors is compared with TARMOS predictions and related to the simultaneously collected blur and beam wander data. Related to this, data on the signal correlations from the various MSRT apertures provide information on the transverse atmospheric coherence length $\rho_{0}$, which parameter is directly linked to the blur. Examples are shown of the wavelength dependence of scintillation, predicted from the theory of weak turbulence, in comparison with the 3-band scintillation data from the MSRT sensor. In the comparison of the local and path-averaged scintillation, the effect of path inhomogeneities of the atmospheric conditions along the path is taken into account. Conditions with low scintillation are getting special attention, as they do not always correspond to conditions with small blur.
\end{abstract}

KEYWORDS: scintillation, turbulence, marine boundary layer, littoral waters

\section{INTRODUCTION}

In previous papers on the FATMOSE trials, coordinated from the Institute for Maritime Technology IMT in Simon's Town (South Africa), details of the set-up have been given as well as a variety of results. In a preliminary paper [1], first results were presented, showing examples of the major topics of interest: aerosol distributions, refraction, atmospheric blur and scintillation. In the paper on aerosol distributions [2], it is demonstrated how to retrieve them from multiband transmissometry data. The paper also shows histograms of transmission levels for the measurement range of $15.7 \mathrm{~km}$. In the paper on refraction [3], measured angles of arrival are compared with predictions, based upon the Monin-Obukhov theory of the atmospheric boundary layer. In this theory the vertical temperature profile of the atmosphere is predicted as well as the structure parameter for the refractive index: $\mathrm{C}_{\mathrm{n}}{ }^{2}$. The paper also contains a comparison of the measured and predicted $\mathrm{C}_{\mathrm{n}}^{2}$. Another paper [4] was prepared on the results of atmospheric blur and beam wander measurements, which also contains probability distributions of these parameters for the period of about a year. The results of the experiments are of great operational interest for the users of electro-optical instruments in coastal areas.

The effect of scintillation may lead to enhanced detection capabilities for optical and IR threat detection systems, as peak signals tend to exceed the mean signal level generally by a factor 3 or more [5]. It was found, that the magnitude of the scintillation increases with range. It was also found that heavy signal fluctuations generally occur, when targets pop-up

Optics in Atmospheric Propagation and Adaptive Systems XV, edited by Karin Stein, John Gonglewski, Proc. of SPIE Vol. 8535, 853504 - (c) 2012 SPIE · CCC code: 0277-786/12/\$18 · doi: 10.1117/12.970566 
over the horizon due to sub-refractive effects in the lowest part of the atmospheric boundary layer [6]. The fluctuations in signal level due to this phenomenon are however not described by scintillation theory, similar to some other atmospheric and instrumental effects [7]. In this paper the results of the signal statistics in various weather conditions are presented, accompanied with a discussion on the validity of the weak turbulence theory for the $15.7 \mathrm{~km}$ range. The log-normal behaviour is investigated, together with potential saturation. The probability distribution of the level of the Scintillation Index (SI) the during a year is presented together with that of $\mathrm{C}_{\mathrm{n}}{ }^{2}$. Temporal spectra related to the signal fluctuations are presented, where a comparison is made with the theoretical " $-5 / 3$ " power law of Kolmogorov. Additional spectra of windspeed and temperature fluctuations are presented, as collected with the sonic anemometer.

A variety of correlations is described, especially between the scintillation data along the long path and the short range scintillometer data. This analysis further includes the predictions from the windspeed and air temperature fluctuations of the sonic anemometer and even more indirectly via the bulk atmospheric parameters: air and water temperature, pressure, relative humidity and windspeed, following the Monin-Obukhov theory [8]. Other correlations concern the SI for three different wavelengths, where the weak turbulence theory predicts a decrease with wavelength $\lambda$ according to $\lambda^{-7 / 6}$ [9]. As the three apertures for these wavelengths are spatially separated, the correlation between the signal fluctuations of them is investigated, which potentially contains information on the transverse coherence length $\rho_{0}$. Special attention is given to potential non-correlation due to variations of the water temperature along the path, which is likely to occur in the False Bay, where water of the cool Benguela current and warm Agulhas current are mixed [10]. It is known, that the Air to Sea Temperature Difference (ASTD) is of major influence on the magnitude of $\mathrm{C}_{\mathrm{n}}{ }^{2}$ [11], so ASTD variations along the path create a mix of $\mathrm{C}_{\mathrm{n}}{ }^{2}$ values. As the main instrumental details of the FATMOSE set-up are given already in references [1] to [4], a limited summary is given in section 2. In the other sections, examples are shown of data of one special event, data covering less than one day and data of several consecutive days. Finally a selection is made of significant events during the whole FATMOSE period, estimated to represent the most important turbulence and weather conditions.

\section{INSTRUMENTAL DETAILS}

The South African False Bay between Simon's Town (IMT) and Strandfontein is an ideal location for experiments on atmospheric propagation. Due to the great variability of weather conditions, which are frequently stable for several days with prevailing wind directions (South-East), perpendicular to the Line of Sight (North-East). After a succesful first twoweek experiment in 2007 [12], it was decided to set-up the long-duration FATMOSE experiment in 2009, with a very extensive set of instruments, as described in references [1] to [4]. In this section, only details are given of the equipment, involved in the scintillation (and blur) measurements.

IMT location; At IMT the two imaging sensors and the MSRT radiometer were mounted on one tripod, located inside the building in a room at an altitude of $14.5 \mathrm{~m}$ AMSL. On the roof at an altitude of $\sim 24 \mathrm{~m}$ above mean sea level (AMSL) two standard weather stations were installed (IMT and TNO), with additional rain-, visual- and IR sky radiance sensors . The main characteristics of the (TNO) sensors are as follows:

- Celestron; an 8-inch telescope, $\mathrm{f} / 10$ was used with a focal length of $2030 \mathrm{~mm}$. In the focal plane a 10 bits Marlin F-033B camera with $640 \times 480$ pixels was mounted. The size of the pixels is $10 \times 10 \mu \mathrm{m}$, which provides a DAS of $5 \times 5 \mu \mathrm{rad}$. The camera, having a frame rate of $30 \mathrm{~Hz}$, is supplied with a near-IR filter, which limits the spectral sensitivity to a band around $0.8 \mu \mathrm{m}$. Each 5 minutes a series of consecutive 150 frames were recorded and processed on a PC station. The field of view of the Celestron is $3.2 \times 2.4 \mathrm{mrad}$. A Matlab script, developed at TNO, allows a direct analysis of the main characteristics of the image of the spot: the blur, the beam wander and the SI, which simplifies and accellerates the data interpretation considerably. The software provides information on the signal level, necessary for the selection of the proper integration time (100 $\mu$ s or more).

- $\quad$ MSRT; three spectral bands with sufficient $\mathrm{S} / \mathrm{N}$ ratio were selected around the centre wavelengths of 0.6, 0.9 and $1.5 \mu \mathrm{m}$ (ch2, ch3 and ch4). The integration time of the lock-in amplifiers was set to $10 \mathrm{~ms}$, while the data were sampled with a frequency of $200 \mathrm{~Hz}$. Each minute a set of 4200 data samples were collected in 21 seconds and stored in the remaining time. Monitoring of the signal behavior was done locally; data processing was done afterwards. The integration time for the scintillation measurement was $10 \mathrm{~ms}$, resulting in a $\mathrm{S} / \mathrm{N}$ ratio of 400 (for a transmission level of 1) for ch4. For the transmission measurement an integration time of $1 \mathrm{~s}$ was used. The entrance pupils of ch2 and ch 4 are $11.5 \mathrm{~cm}$ horizontally separated, while the pupils of ch 3 and ch 4 are $6 \mathrm{~cm}$ vertically separated. 
Roman Rock location; a standard weather station was installed on the lighthouse, providing every five minutes the air temperature and relative humidity, windspeed and -direction, air pressure and solar irradiation. Power was delivered from batteries, charged with solar panels. Data were transmitted by radio link to IMT, together with the data from the other sensors on the lighthouse. All sensors (except the visibility sensor at $9 \mathrm{~m}$ AMSL) were mounted on the upper rail on the SW side of the lighthouse at an altitude of $15 \mathrm{~m}$ AMSL. Details on the additional sensors are given below.

- IR radiometer; the Heitronics KT 15.8511P long wave IR (9.6-11.5 $\mu \mathrm{m})$ radiometer was used to measure the sea surface temperature (SST). This radiometer has a small field of view $\left(2.6^{\circ}\right)$ and looks downward under an angle of $55^{\circ}$ with the horizon, as shown in Figure 1 (left). Corrections are made for cold sky reflectance.

- Scintillometer; the Scintec BLS 900 system uses a double source with a diameter of $150 \mathrm{~mm}$, each with 462 LEDs, mounted on the lighthouse (Figure 1 centre). The receiver (diameter $150 \mathrm{~mm}$ ) was mounted on the roof at IMT. The receiver measures the scintillation along the $1.8 \mathrm{~km}$ path. Data were collected each two minutes

- Sonic anemometer; this device (Gill R3A, Figure 1 right) measures the speed of sound in three orthogonal directions together with the air temperature, with a sampling rate of $100 \mathrm{~Hz}$. These data are directly converted into windspeeds in $\mathrm{X}, \mathrm{Y}$ and $\mathrm{Z}$-direction, from which atmospheric turbulence can be determined. This device was installed from April to October 2010. In each period of five minutes, 30000 data samples were collected. Analysis software provides turbulence parameters such as TKE (Turbulent Kinetic Energy) and TI (Turbulent Intensity), as well as the mean windspeed and -direction. The sonic anemometer was mounted near the Southern side of the lighthouse to minimise the turbulence effects of the lighthouse construction for SE wind conditions.
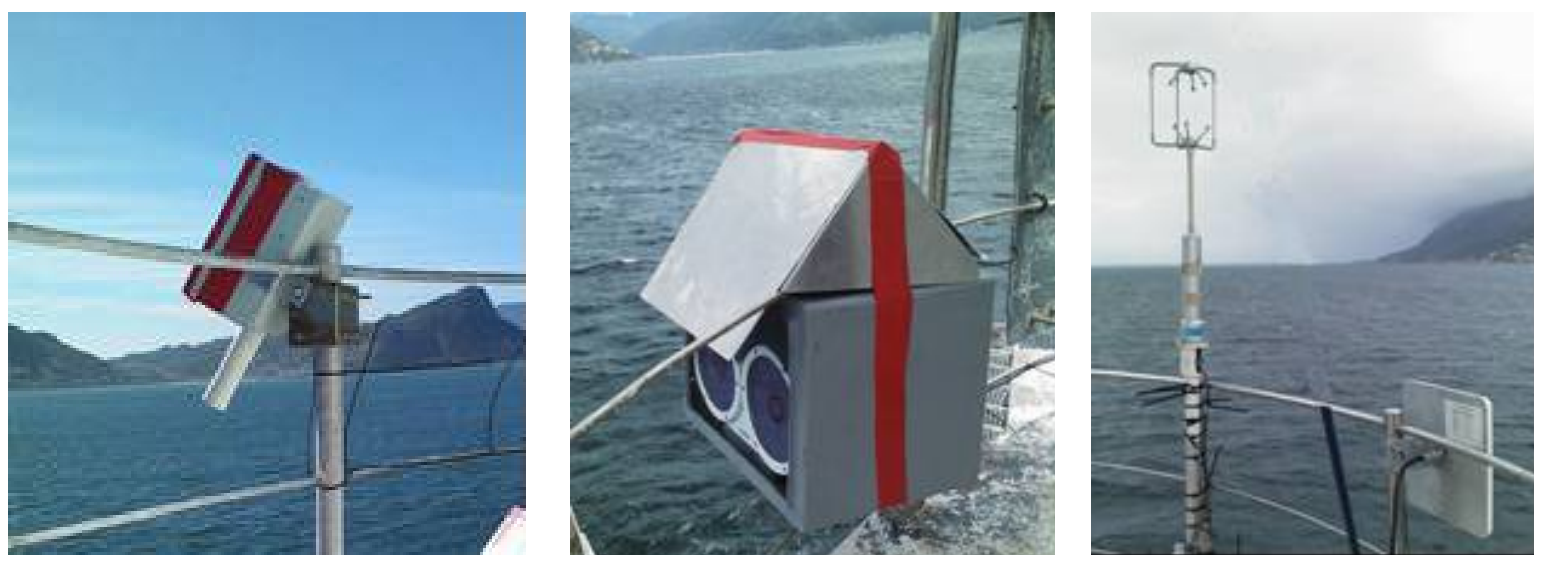

Figure 1. Pictures of advanced weather sensors on Roman Rock Lighthouse: Heitronics KT 15.8511P radiometer (left), sources of Scintec BLS 900 scintillometer (centre), and Gill R3A sonic anemometer (right)

NSRI station; on the roof of this building four sources were mounted. The height of the MSRT source and the Topcon source was about $8.7 \mathrm{~m}$ AMSL. The height of the two central sources, used by the Celestron camera is 9.7 and $5.8 \mathrm{~m}$ AMSL. The modulated MSRT source has a diameter of $20 \mathrm{~cm}$. The other three DC sources (basically search lights for cars with a diameter of $150 \mathrm{~mm}$ and a focal length of $30 \mathrm{~mm}$ ), used a 50 Watt quartz halogen lamp. The apertures of the Celestron sources had a reduced diameter $(90 \mathrm{~mm})$ to avoid saturation (even when using an integration time in the Marlin of $100 \mu \mathrm{s}$ ) in cases of extremely good visibility. The modulation frequency of the MSRT was transmitted by radio link. The antenne was mounted directly on the housing for the MSRT source, which was installed to avoid sand and sea spray on the window. The source for the refraction measurements was using the full $150 \mathrm{~mm}$ diameter. As the beam width of the DC sources is quite large (about $2^{\circ}$ ), alignment was not a major problem. The alignment was however a problem for the MSRT source in the first part of the FATMOSE trial, due to the limited vertical beam divergence (4 $\mathrm{mrad}$ ). In March 2010 a new (3x3 mm) lamp was installed, giving a vertical beam divergence of $10 \mathrm{mrad}$. The four sources provided a certain degree of redundancy, but due to the limited lifetime of the lamps, this gave some flexibility in the whole arrangement. The MSRT source can well be used for the Topcon camera, although a certain percentage of the images is missing. Of course a correction has to be made for the source diameter (12.7 $\mu \mathrm{rad})$, in case the MSRT source is used for the blur measurement with the Celestron. Electric power for the four sources was kindly provided during the whole FATMOSE period by the National Sea Rescue Institute in Strandfontein. 


\section{DATA PROCESSING METHOD}

For the retrieval of blur and SI from the raw Celestron data, target windows of about 40x40 pixels were defined around the two sources. Additionally, background windows were taken around these target windows. The mean background signal levels were subtracted from the signal levels in the target areas. Next a threshold level above this remaining signal level was created at three times the standard deviation of the background noise. This was done for each of the 150 frame series. For pixels in both spot areas with signal level I $(x, y)$ above this threshold and the centre of gravity was determined as well as the second moments $\mathrm{M}_{20}$ and $\mathrm{M}_{02}$ in $\mathrm{X}$ and $\mathrm{Y}$ direction and the total integrated signal (intensity). The total blur $\sigma_{t}=\sqrt{ }\left(\sqrt{ } M_{20} * \sqrt{ } M_{02}\right)$ is corrected for camera and source blur to obtain the atmospheric blur $\sigma_{a}$ [4]. The mean beam wander BW is obtained via the relation: $B W=<\sqrt{ }\left\{\left(x_{n}-x_{c}\right) 2+\left(y_{n}-y_{c}\right) 2\right\}>(n=1 \ldots 150)$, where $x_{n}$ and $y_{n}$ are the gravity centres for the $n^{\text {th }}$ frame and $x_{c}$ and $y_{c}$ are the mean centre positions for the series of 150 frames. The intensity $I_{n}$ (for the $n^{\text {th }}$ frame) is calculated via: $I_{n}=\iint I(x, y) d x d y(n=1 \ldots 150)$. The mean $I_{m}$ and the standard deviation $I_{s}$ of the series are determined, from which the scintillation index SI is obtained: $\mathrm{SI}=\left(\mathrm{I}_{\mathrm{s}} / \mathrm{I}_{\mathrm{m}}\right)^{2}$.

For the 4200 data samples of the MSRT, taken each minute, the mean value $V_{m}$ and the standard deviation $V_{s}$ of the voltage levels was calculated, from which the SI was directly obtained: $\mathrm{SI}=\left(\mathrm{V}_{\mathrm{s}} / \mathrm{V}_{\mathrm{m}}\right)^{2}$. The resulting $\mathrm{SI}$ is independent of the calibration of the transmission level, but small corrections have to be made for potential offsets. One problem, arising in the analysis of the MSRT data is the sunglint in the sea in morning hours between 09.30 and 10.30. This problem is illustrated in Figure 2, with a picture of the 4 sources and the sunglint on 6 April 2010, taken by the Celestron telescope and of SI and transmission recordings from the MSRT. For these periods the SI values channels 2 and 3 are largely influenced by the rapidly changing sun-spikes. The transmission value for channel 4 is not influenced by the sunglints.
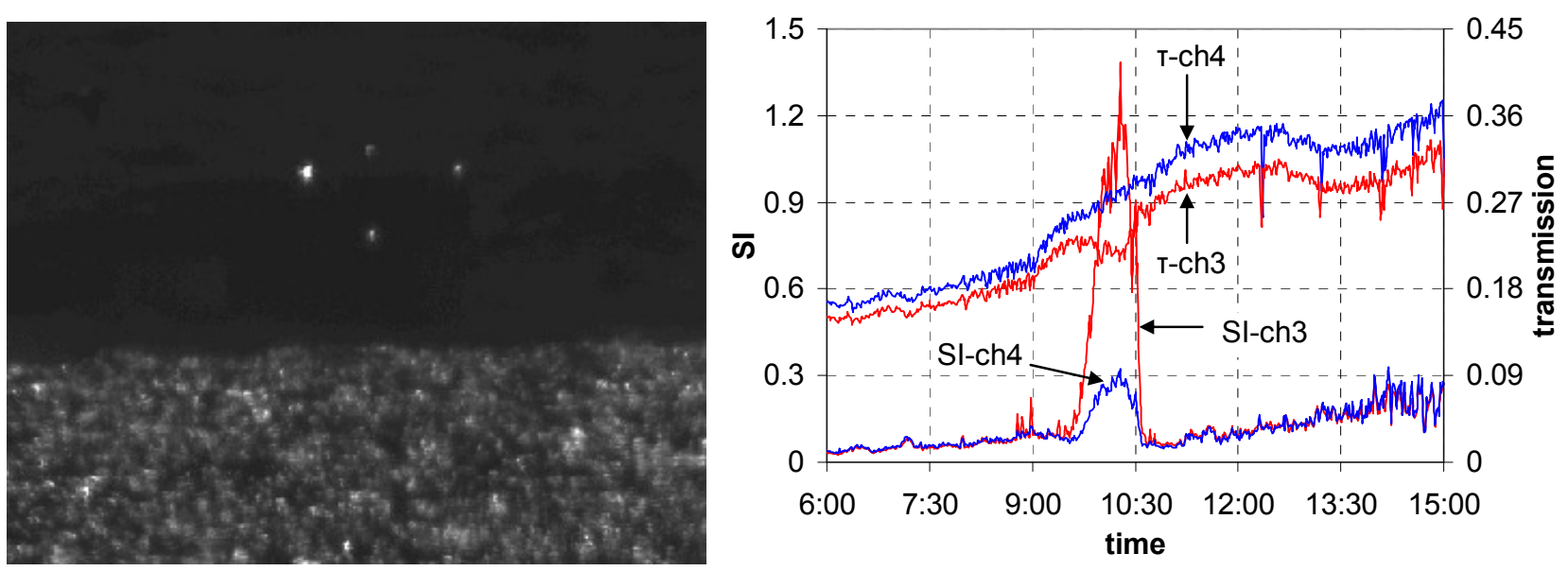

Figure 2. Influence of sunglints in the water on the SI values in the morning hours between 09.30 and 10.30 .

For the Scintec BLS 900 scintillometer, the $\mathrm{C}_{\mathrm{n}}{ }^{2}$ value is obtained via the log-amplitude variance $\mathrm{B}$, calculated from the variance $\sigma$ of the signal and the mean signal $\mathrm{I}_{1}$ by the relation: $\mathrm{B}=0.25^{*} \ln \left(1+\sigma /\left(\mathrm{I}_{1}\right)^{2}\right) . \mathrm{C}_{\mathrm{n}}{ }^{2}$ follows next from the relation: $C_{n}^{2}=4.63 * B *\left(D_{t}\right)^{7 / 3} * R^{-3}$, where $D_{t}$ is the diameter of the transmitter $(0.15 \mathrm{~m})$ and $R$ the range $(1800 \mathrm{~m})$. More details on the retrieval procedure are given in the manual [13]. Concerning the sonic anemometer, the wind parameters in the frame of reference $(\mathrm{X}, \mathrm{Y}, \mathrm{Z})$ are translated into a natural coordinate system, parallel and orthogonal to the mean wind vector, as described in the manual of Gill instruments [14]. The new windparameters are splitted into mean values and fluctuations. If these fluctuations in the vertical plane through the mean wind vector are called $\mathrm{u}(\sim$ horizontal $)$ and $\mathrm{w}(\sim \mathrm{vertical})$, a direct calculation of the friction velocity $\mathrm{u}_{*}$, the scaled temperature $\mathrm{T} *$ and the Obukhov length $\mathrm{L}_{\mathrm{ob}}$ follows:

$$
\mathrm{u}_{*}{ }^{2}=-<\mathrm{wu}>\quad \mathrm{T}_{*}=-<\mathrm{wt}>/ \mathrm{u}_{*} \quad \mathrm{~L}_{\mathrm{ob}}=\left(\mathrm{T}_{\mathrm{m}} \mathrm{u}_{*}{ }^{2}\right) /\left(\mathrm{KgT}_{*}\right)
$$

where $T_{m}$ is the mean temperature and $t$ the fluctuation around $T_{m} ; K$ is the von Karman constant $(0.4)$ and $g$ the gravity accelleration $\left(9.8 \mathrm{~m} / \mathrm{s}^{2}\right)$. The symbol $<>$ stands for the covariance of two fluctuations. The relations for the scaling parameters $\mathrm{u}_{*}$ and $\mathrm{T} *$ are to be considered as their definitions. According to the theory of the micrometeorological 
boundary layer [8], they are also connected to the vertical transport of momentum and heat. The Obukhov length scale $\mathrm{L}_{\mathrm{ob}}$ is considered as the characteristic height scale of the sublayer of dynamic turbulence and appears in the so called stability parameter $\mathrm{z} / \mathrm{L}_{\mathrm{ob}}$, where $\mathrm{z}$ is the height. With the relations (1) the structure parameters for the temperature $\mathrm{C}_{\mathrm{T}}{ }^{2}$ and for the refractive index $\mathrm{C}_{\mathrm{n}}^{2}$ can be calculated by means of the relations:

$$
\mathrm{C}_{\mathrm{T}}{ }^{2}=\mathrm{z}^{-2 / 3} \mathrm{~T} * \mathrm{f}\left(\mathrm{z} / \mathrm{L}_{\mathrm{ob}}\right) \quad \mathrm{C}_{\mathrm{n}}{ }^{2}=\left(79 * 10^{-8} \mathrm{p} / \mathrm{T}_{\mathrm{m}}{ }^{2}\right)^{2 *} \mathrm{C}_{\mathrm{T}}{ }^{2} \approx 10^{-12 *} \mathrm{C}_{\mathrm{T}}{ }^{2}
$$

where $\mathrm{p}$ is the atmospheric pressure $\left(\mathrm{N} / \mathrm{m}^{2}\right)$ and $\mathrm{f}\left(\mathrm{z} / \mathrm{L}_{\mathrm{ob}}\right): 4.91 *\left(1-7.0 * \mathrm{z} / \mathrm{L}_{\mathrm{ob}}\right)^{-2 / 3}$ for $\mathrm{L}_{\mathrm{ob}}<0$ and $4.91 *\left(1+2.4 * \mathrm{z} / \mathrm{L}_{\mathrm{ob}}\right)^{2 / 3}$ for $\mathrm{L}_{\mathrm{ob}}>0$. The value, thus obtained for $\mathrm{C}_{\mathrm{n}}^{2}$ is based upon locally collected weather data. Also local, but obtained in a more indirect way is the $\mathrm{C}_{\mathrm{n}}{ }^{2}$, based upon the Monin-Obukhov theory as implemented in the TARMOS model, developed at TNO [11]. In this model a set of boundary layer equations is solved in an iterative way by using standard weather parameters as input. This model did work quite well in FATMOSE [3]; for conditions of low windspeed $(<2 \mathrm{~m} / \mathrm{s})$ and small ASTD values the relation with really measured $\mathrm{C}_{\mathrm{n}}^{2}$ values is not so good. Apparently the mechanism of transport of momentum and heat is more complicated in these conditions than assumed by theory.

\section{SINGLE SAMPLE STATISTICS}

An important check in collected scintillation data is the log-normality of their distributions. Validation of this behaviour provides an indication of potential saturation effects. In the set-up of the MSRT, electronic saturation was avoided by proper gain settings of the signal amplifiers, keeping the maximum output voltage levels below $10 \mathrm{Volt}$ for the highest visibility conditions. Saturation of scintillation, which may occur when using small sources and receivers, results in the absence of the log-normality and generally limits the SI to values of about 1. For a number of MSRT data samples, taken in different scintillation conditions, histograms of the normalised signals (which are proportional to the pupil irradiance), were investigated. Some typical examples are shown in Figure 3 for low scintillation conditions (5 April 22.00) and high scintillation conditions (13 August 19.30)
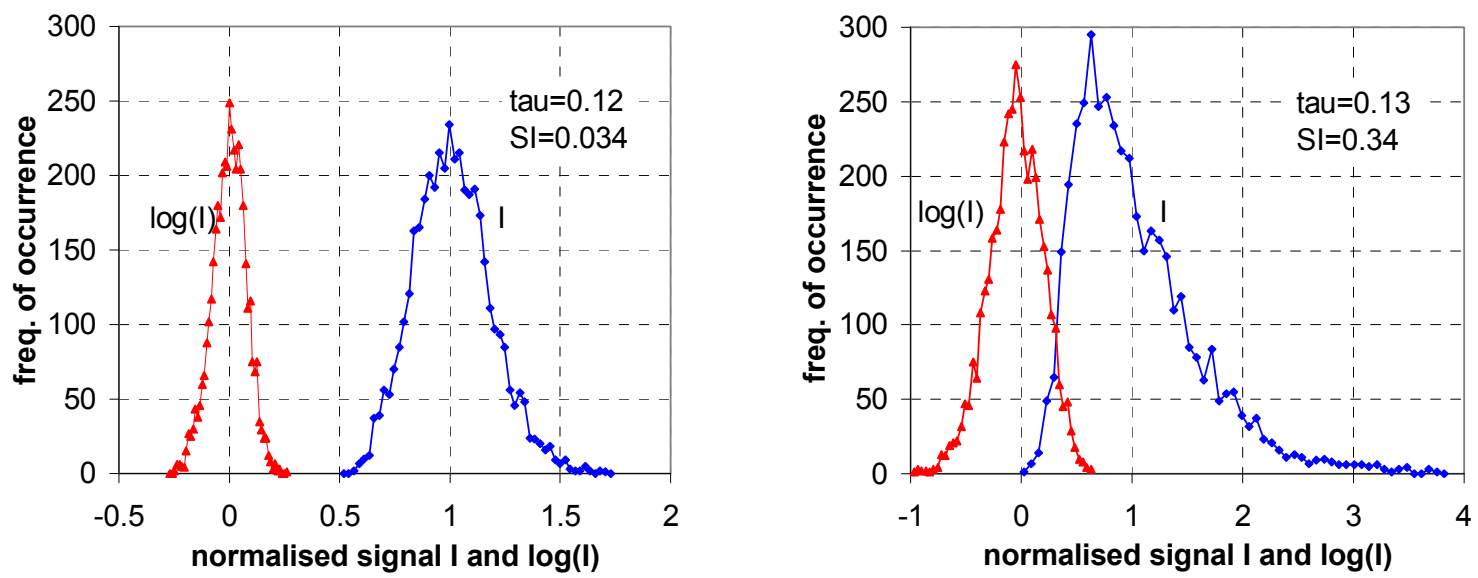

Figure 3. Histograms of MSRT signals for low ( $\mathrm{SI}=0.034$, left) and high scintillation conditions $(\mathrm{SI}=0.34$, right $)$

It is observed, that the log-normality for low scintillation conditions ( $\mathrm{SI}=0.034)$ is hardly present and the distributions of the normalised signal I and its $\operatorname{logarithm} \log (\mathrm{I})$ are close to a Gaussian shape. For high scintillation conditions however $(\mathrm{SI}=0.34)$, the distributions show a more pronounced log-normal shape. This is another indication of the validity of the Rytov approximation for the electric field $\mathrm{E}$, inserted into the wave equation for weak turbulence: $\mathrm{E}=\exp (\Psi)=\exp (\chi+\mathrm{iS})$, where $\chi$ is the so-called log-amplitude $\ln (\mathrm{A})$, A the amplitude and $\mathrm{S}$ the phase. Rytov's theory predicts values for the variance of $\chi: \sigma_{\chi}^{2}$, which is related to SI by the relation: $S I=\exp \left(4 \sigma_{\chi}^{2}\right)-1$. This reduces to approximately $4 \sigma_{\chi}^{2}$ for weak turbulence [9], for which Rytov's theory (applicable for $\sigma_{\alpha}^{2}<0.3$ ) predicts the following relation for SI (plane wave, point source and receiver): $\mathrm{SI}_{R}=1.23 \mathrm{C}_{\mathrm{n}}^{2}(2 \pi / \lambda)^{7 / 6} \mathrm{~L}^{11 / 6}$, where $\lambda$ is the wavelength and $\mathrm{L}$ the path length. It is noted, that weak turbulence conditions can change into strong turbulence conditions for longer path lengths. The histograms (channel 4) cover 21 seconds of data (4200 data points), while the transmission level tau (channel 3) was higher than 10\%. 
In addition to the path averaged scintallation data, histograms were made of local turbulence data, collected by the sonic anemometer at Roman Rock Lighthouse. A strong wind $(\sim 14 \mathrm{~m} / \mathrm{s})$ was blowing for days from the South East, the "good" side for the sonic anemometer. The histograms show about normal distributions with standard deviations of $1.34 \mathrm{~m} / \mathrm{s}$, $3.94^{\circ}$ and $0.43 \mathrm{~K}$ for the windspeed, wind direction and temperature. The side peaks in the wind direction are due to the sonic data processing method. The variations in the windspeed in the three orthogonal directions can be used to calculate turbulence parameters such as the turbulent kinetic energy and the turbulent intensity, but are less essential for prediction of $\mathrm{C}_{\mathrm{n}}^{2}$, where covariances of $\mathrm{u}$, $\mathrm{w}$ and $\mathrm{t}$ are used (as shown in equations (1)).
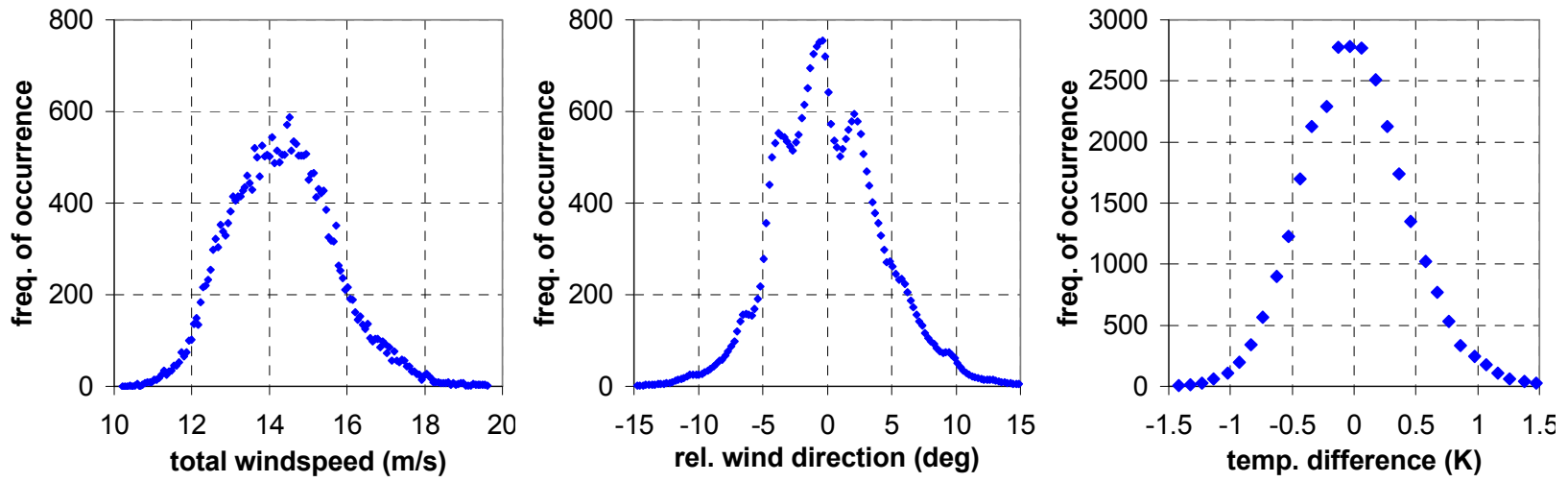

Figure 4. Histograms of sonic windspeed, wind direction and temperature data for 1 April 04.00 (5 minutes of data).

Another interesting topic is the temporal spectrum, as determined from the same data series of the MSRT and the sonic. Concerning the MSRT spectrum, shown in Figure 5 (left) on log-log scales, the question is if there is any correspondence with the Kolmogorov theory for turbulence, predicting a one dimensional spatial spectrum, proportional to $\kappa^{-5 / 3}$, where $\kappa$ is the spatial frequency. According to Taylor's hypothesis of frozen turbulence [9], the temporal spectrum should have the same shape. The MSRT spectra show indeed a decline with appropriate slope above a frequency of $10 \mathrm{~Hz}$. The slope is rather independent of SI and appeared to vary from 1.35 to 2.1 (mean 1.78) for a selection of 24 events. Below $10 \mathrm{~Hz}$ the spectrum is nearly flat, which should, according to Kolmogorov, occur below $1 \mathrm{~Hz}$.
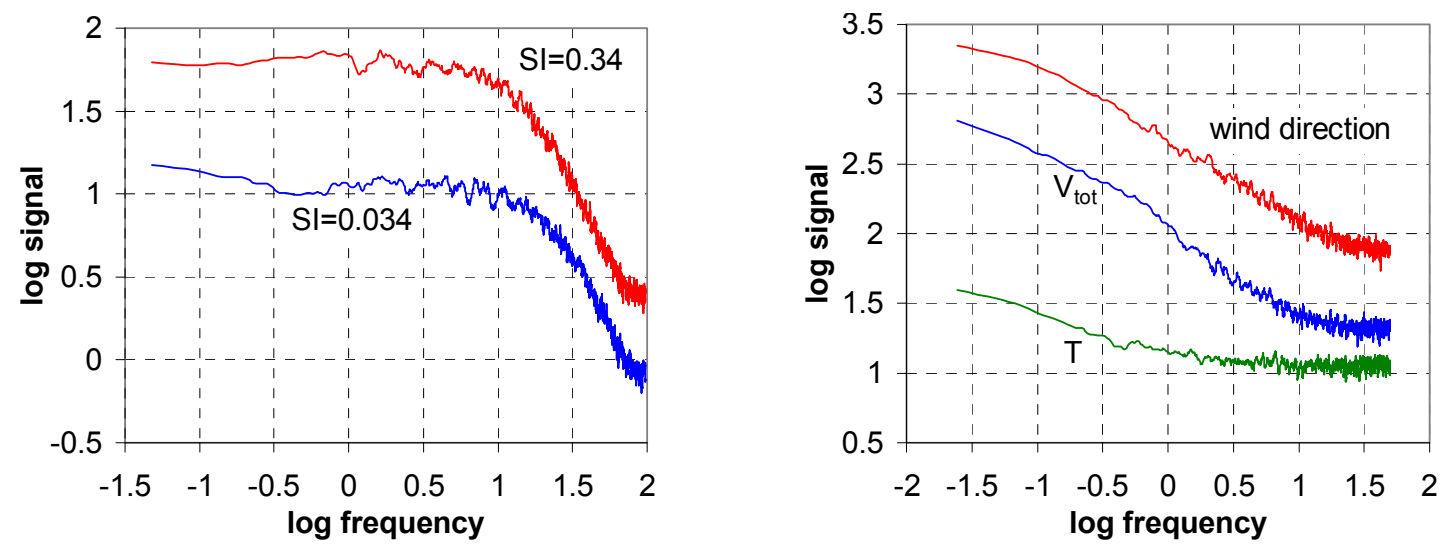

Figure 5. Temporal spectra of MSRT (left) and sonic (right) data fluctuations for the same events as in Figures 3 and 4.

The sonic spectra, shown in Figure 5 (right), should be in agreement with the 2/3 power law for the longitudinal velocity component $\mathrm{V}_{\text {tot }}$. This slope is found to be correct for frequencies between 1 and $10 \mathrm{~Hz}$, which corresponds to eddies of sizes between 15 and $1.5 \mathrm{~m}$ (for a windspeed of $15 \mathrm{~m} / \mathrm{s}$ ). The spectrum of the wind direction shows nearly the same slope as the $V_{\text {tot }}$ spectrum, which indicates that the spectra are about similar in all directions. The spectrum for the temperature fluctuations becomes flat above frequencies of $1 \mathrm{~Hz}$, which means that temperature fluctuations are relatively bigger for smaller eddies (stronger gradients). This may have an impact on the optical turbulence effects (blur, beam wander and scintillation) for longer atmospheric paths. 


\section{SONIC-SCINTEC-TARMOS COMPARISON}

In this section, measured $\mathrm{C}_{\mathrm{n}}{ }^{2}$ data are compared with TARMOS predictions, based upon weather data, taken at Roman Rock Lighthouse. From the sonic data, $\mathrm{C}_{\mathrm{n}}^{2}$ is obtained following the procedure, described in section 3 , providing one data point each five minutes. The BLS-900 data, collected each two minutes, are converted into a synchronised data set. Figure 6 shows a one day data set, collected on 11 April with SE wind and a windspeed of more than $10 \mathrm{~m} / \mathrm{s}$. A drop in $\mathrm{C}_{\mathrm{n}}{ }^{2}$ level of about a factor 10 is observed during the transit of the morning hours towards the afternoon hours. Similarly the levels of blur and SI are dropping. The explanation for this drop is the simultaneous increase of the air temperature during that day (reducing the ASTD from about -2 to $0 \mathrm{~K}$ ), while all the other weather parameters stayed about the same (relative humidity 80\%). Data averaging was applied (30 minutes) in order to reduce the "noise". The figure shows that for this day the local sonic and TARMOS data are corresponding reasonably well with the BLS scintillometer data. The drop in SI level is also about a factor 10, which illustrates the proportionality of SI and $\mathrm{C}_{n}{ }^{2}$ and is in agreement with the theory of weak turbulence [9]. It is noted, that the SI data from the MSRT and the Celestron imager are matching quite good for most of the time, apart from the morning sunglint period, as discussed before (Figure 2). It is also noticed that the drop in blur level of about a factor 2 (from roughly 4 to 2 pixels or 20 to $10 \mu \mathrm{rad}$ ) is less than predicted from the theory of weak turbulence. This prediction states a proportionality of blur with $\left(\mathrm{C}_{\mathrm{n}}{ }^{2}\right)^{0.6}$, corresponding with a factor 4 from the morning to the afternoon hours.

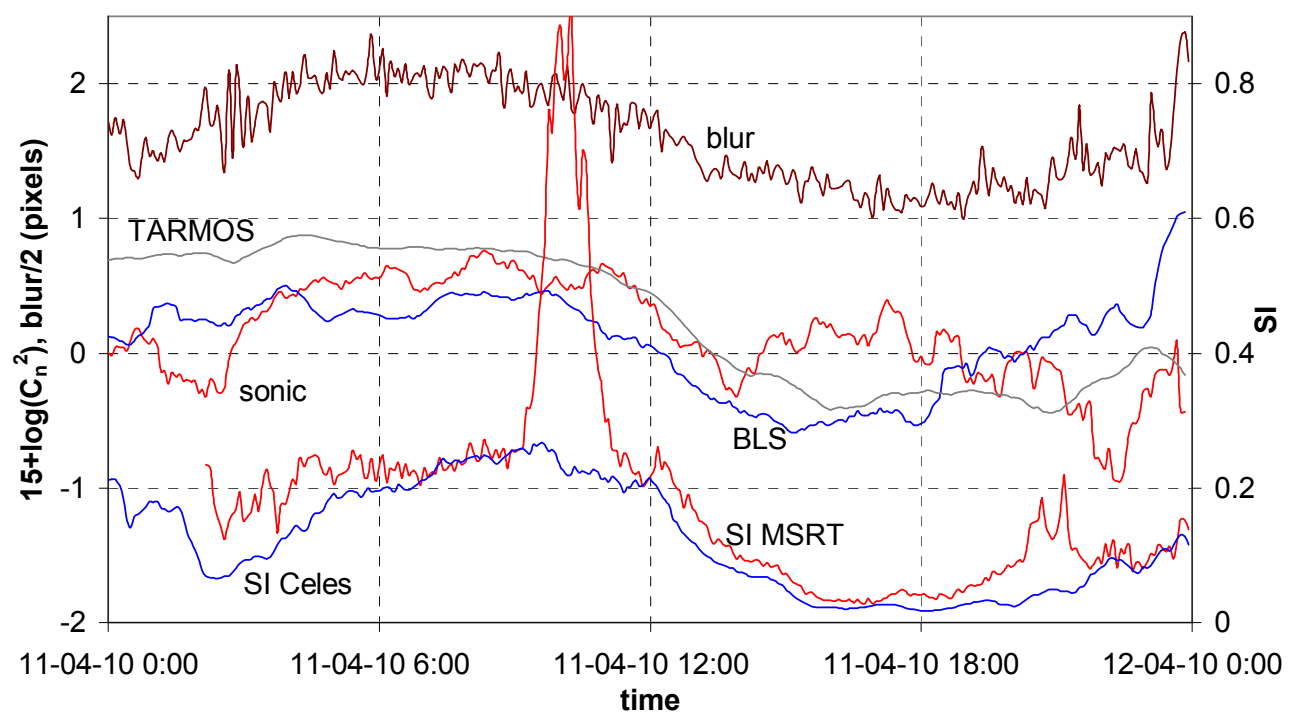

Figure 6. Comparison of $\mathrm{C}_{\mathrm{n}}{ }^{2}$ (sonic, BLS, TARMOS), scintillation (MSRT, Celestron) and blur from different sensors

The good correspondence between the various sources of $\mathrm{C}_{\mathrm{n}}^{2}$ on this particular day is due to the stability of most of the weather parameters. The mean differences of the $\log \left(\mathrm{C}_{\mathrm{n}}{ }^{2}\right)$ values of the BLS and sonic, and of the BLS and TARMOS are 0.06 respectively 0.18 . This is remarkable if it is realised, that in the calculation procedure of $\mathrm{C}_{\mathrm{n}}^{2}$ from the variance of the irradiance for the BLS, assumptions are made for the 3-D spectrum of the refractive index fluctuations, following the Kolmogorov spectrum (proportional to $\mathrm{K}^{-11 / 3}$ ) between the inner and outer scale of turbulence and being zero outside that region. Based upon the measured spectrum, as shown in Figure 5, one might conclude that this assumption is not valid in all circumstances and that other spectra, as described by Andrews ([15], chapter 3) may be applicable over the False Bay. Different spectra will thus result in different $\mathrm{C}_{\mathrm{n}}{ }^{2}$ values. It is worthwile to note, that the Fresnel length scale $\left(\lambda \mathrm{L}_{1}\right)^{1 / 2}$ for the BLS set up, with wavelength $\lambda$ being $0.88 \mu \mathrm{m}$ and path length $\mathrm{L}_{1}=1.8 \mathrm{~km}$ resulting in a Fresnel length of $4 \mathrm{~cm}$, stays well within the inner scale $\mathrm{l}_{0}(\sim 3 \mathrm{~mm})$ and outer scale $\mathrm{L}_{0}(10-100 \mathrm{~m})$ of turbulence.

Another example with compared $\mathrm{C}_{\mathrm{n}}^{2}$ data is shown in Figure 7, for a three days period (3-6 April) with stable weather conditions: wind from the South East, windspeed $>10 \mathrm{~m} / \mathrm{s}$, relative humidity $\sim 80 \%$, ASTD fluctuating around zero. The trend in the ASTD is a change from $+1 \mathrm{~K}$ in the beginning towards $0 \mathrm{~K}$ in the end, with a dip of $-1 \mathrm{~K}$ on 5 April around 06.00. This trend should be observable but is not found in the $\mathrm{C}_{\mathrm{n}}^{2}$ trends as determined from the Roman Rock sensors. 
The - $1 \mathrm{~K}$ dip is only (obviously) found by the TARMOS prediction, as ASTD is a major input parameter for this code. The higher $\mathrm{C}_{\mathrm{n}}{ }^{2}$ level until 3 April 18.00, may be associated with the higher absolute humidity level and the cloud cover, disappearing after this moment. The mean differences of the $\log \left(\mathrm{C}_{\mathrm{n}}^{2}\right)$ values of the BLS and sonic, and of the BLS and TARMOS are respectively 0.09 and 0.16 , similar to the previous example. The ASTD trend however is found back in the SI trend, as collected by both long path scintillation sensors, showing a decrease in SI level from about 0.2 to 0.04 . The ASTD dip of $-1 \mathrm{~K}$ is not found however, probably due to the locality of the dip around Roman Rock.

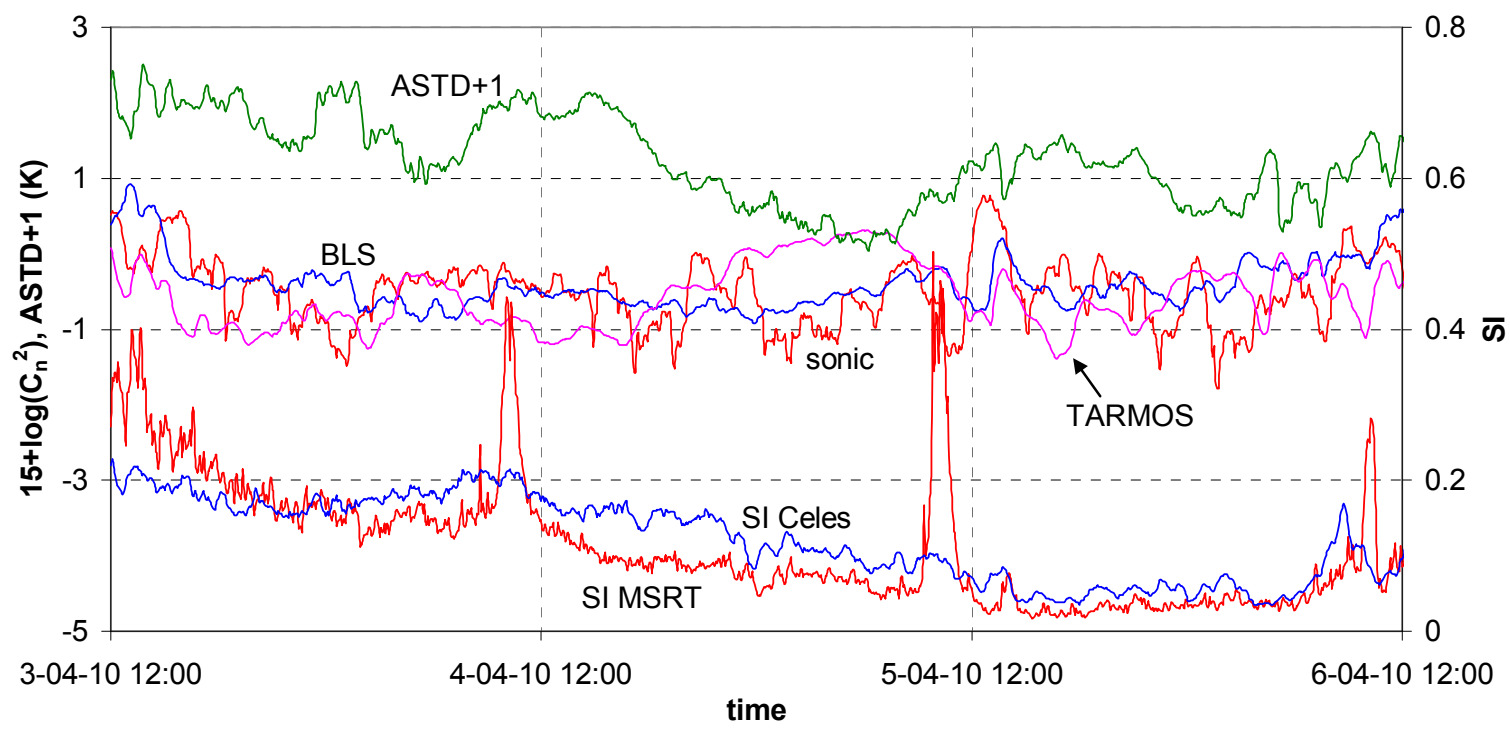

Figure 7. As Figure 6 for three days period from 3 April 12.00 to 6 April 12.00

It may be concluded that in general the mean $\mathrm{C}_{\mathrm{n}}^{2}$ values, obtained for a period of one day or more from the three basic sources correspond within a factor 1.5 or better. This means, that all three candidates may provide useful information for long term atmospheric turbulence statistics. One should be careful however to use their output for simultaneous long range applications, as the likelyhood of path-homogeneity is small. Especially in the False Bay (but probably also for other, similar coastal locations with tidal currents associated with upwelling cold and warm water), surface temperature variations of several degrees may occur along the $15.7 \mathrm{~km}$ path, not found for the $1.8 \mathrm{~km}$ path. All three sources have their weak points: TARMOS, using the IR radiometer, has problems with low windspeed $(<2 \mathrm{~m} / \mathrm{s})$; the sonic, being only useful with South Easerly winds and the BLS scintillometer, making use of the Kolmogorov spectrum.

\section{SCINTILLATION DATA - TIME SERIES}

Until now the $\mathrm{C}_{\mathrm{n}}^{2}$ values of the scintillometer have been compared with the SI data from the MSRT and the Celestron in a qualitative way. In this section the comparison will be made more quantitatively by first considering, that due to the long measurement path the theory for weak turbulence is not applicable any more. In addition, the extended sources and receivers lead to aperture averaging, intentionally used by Scintec in the BLS scintillometer and introduced by Wang and Clifford [16] for reasons of more versatility. For quantifying the aperture averaging factor A, giving the ratio of the SI's for receivers with diameter D and zero, the approximations, given by Andrews [15] (strong turbulence) are taken:

$$
\begin{gathered}
\mathrm{A}=\mathrm{SI}(\mathrm{D}) / \mathrm{SI}(0) \quad \text { where } \quad \mathrm{SI}(\mathrm{D})=\exp \{\mathrm{P}+\mathrm{Q}\}-1 \quad \text { and } \quad \mathrm{SI}(0)=\mathrm{SI}(\mathrm{D}), \text { for } \mathrm{D}=0 \quad \text { with: } \\
\mathrm{P}=0.49 \mathrm{SI}_{\mathrm{R}} /\left(1+0.65 \mathrm{~B}+1.11 \mathrm{SI}_{\mathrm{R}}{ }^{6 / 5}\right)^{7 / 6} \text { and } \mathrm{Q}=\left\{0.51 \mathrm{SI}_{\mathrm{R}}\left(1+0.69 \mathrm{SI}_{\mathrm{R}}{ }^{6 / 5}\right)^{-5 / 6}\right\} /\left\{1+0.9 \mathrm{~B}+0.62 \mathrm{BSI}_{\mathrm{R}}{ }^{6 / 5}\right\} ; \mathrm{B}=\left(\pi \mathrm{D}^{2}\right) /(2 \lambda \mathrm{L})
\end{gathered}
$$

where $\mathrm{SI}_{\mathrm{R}} \approx \mathrm{SI}(0)$ is the Rytov scintillation index for weak turbulence (normalised variance): $\mathrm{SI}_{\mathrm{R}}=1.23 \mathrm{C}_{\mathrm{n}}{ }^{2}(2 \pi / \lambda)^{7 / 6} \mathrm{~L}^{11 / 6}, \lambda$ the wavelength and $\mathrm{L}$ the path length. For the FATMOSE situation: $\lambda=0.8 \mu \mathrm{m}$ and $\mathrm{L}=15.7 \mathrm{~km}, \mathrm{SI}_{\mathrm{R}}$ is varying from 0.067 to 67 for $\mathrm{C}_{\mathrm{n}}{ }^{2}$ values ranging from $10^{-17}$ to $10^{-14}\left(\mathrm{~m}^{-2 / 3}\right)$. The aperture averaging factor A versus the aperture diameter $\mathrm{D}$, 
according to the equations (3) and (4), is shown in Figure 8 (left) for $\mathrm{C}_{\mathrm{n}}^{2}$ values from $10^{-16}$ to $10^{-14} \mathrm{~m}^{-2 / 3}$. For diameters of 4, 9 and $20 \mathrm{~cm}$ (the apertures of the MSRT receiver, the Celestron source and Celestron receiver/MSRT source resp.) the following values for A are found: $0.45,0.23$ respectively 0.136 for a $\mathrm{C}_{\mathrm{n}}^{2}$ value of $10^{-15}$. It is observed, that stronger turbulence results in stronger aperture averaging, but for strong turbulence $\left(10^{-14}\right)$, A drops more quickly for smaller diameters. Figure 8 also shows the variation of $A$ with $\log \left(C_{n}{ }^{2}\right)$ for the three relevant diameters: $A_{4}, A_{9}$ and $A_{20}$. For simplicity the total aperture averaging is taken as the product of the source and receiver aperture averaging: $A_{4} * A_{20}$ for the MSRT and $\mathrm{A}_{9} * \mathrm{~A}_{20}$ for the Celestron. The relations for the two trendlines through these products are respectively: $\mathrm{A}_{4} * \mathrm{~A}_{20}=-0.0692\left\{\log \left(\mathrm{C}_{\mathrm{n}}{ }^{2}\right)\right\}-0.972$ and $\mathrm{A}_{9} * \mathrm{~A}_{20}=-0.0387\left\{\log \left(\mathrm{C}_{\mathrm{n}}{ }^{2}\right)\right\}-0.544$ for the given $\mathrm{C}_{\mathrm{n}}{ }^{2}$ range, which approximations are correct within about $15 \%$.
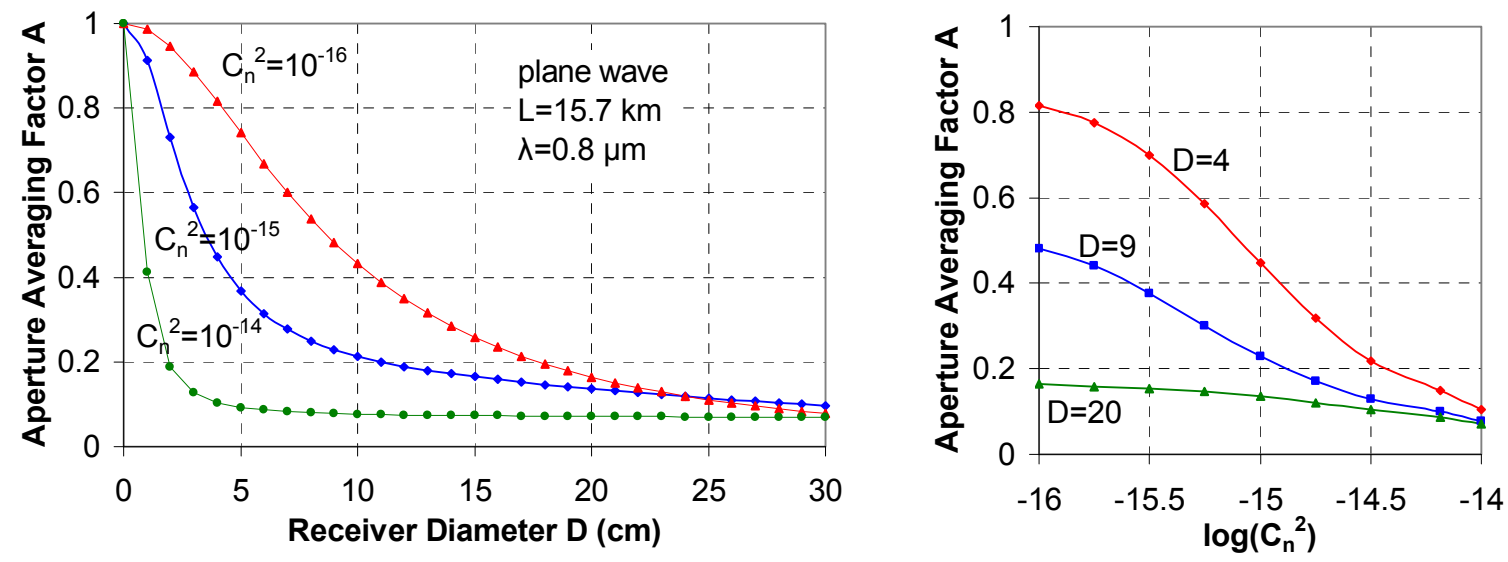

Figure 8. Aperture averaging factor A under strong turbulence conditions as function of diameter $\mathrm{D}$ and $\log \left(\mathrm{C}_{\mathrm{n}}^{2}\right)$

For $\mathrm{C}_{\mathrm{n}}^{2}=10^{-15}$, the total aperture averaging factors become 0.066 (MSRT) respectively 0.037 (Celestron), bringing $\mathrm{SI}_{\mathrm{R}}$ down from 6.7 to 0.44 respectively 0.25 , which is rather close to the measured value of 0.2 (see Figure 6). Before going into more depth, more data from time series will be presented, showing either irregular correlations between the BLS data and the SI data (Figure 9) or good correlations (Figure 10). In the first period, the weather is more variable, starting with low windspeed (from North) and high $\mathrm{C}_{\mathrm{n}}^{2}$, combined with high SI. The other days, the wind direction turns to SE,

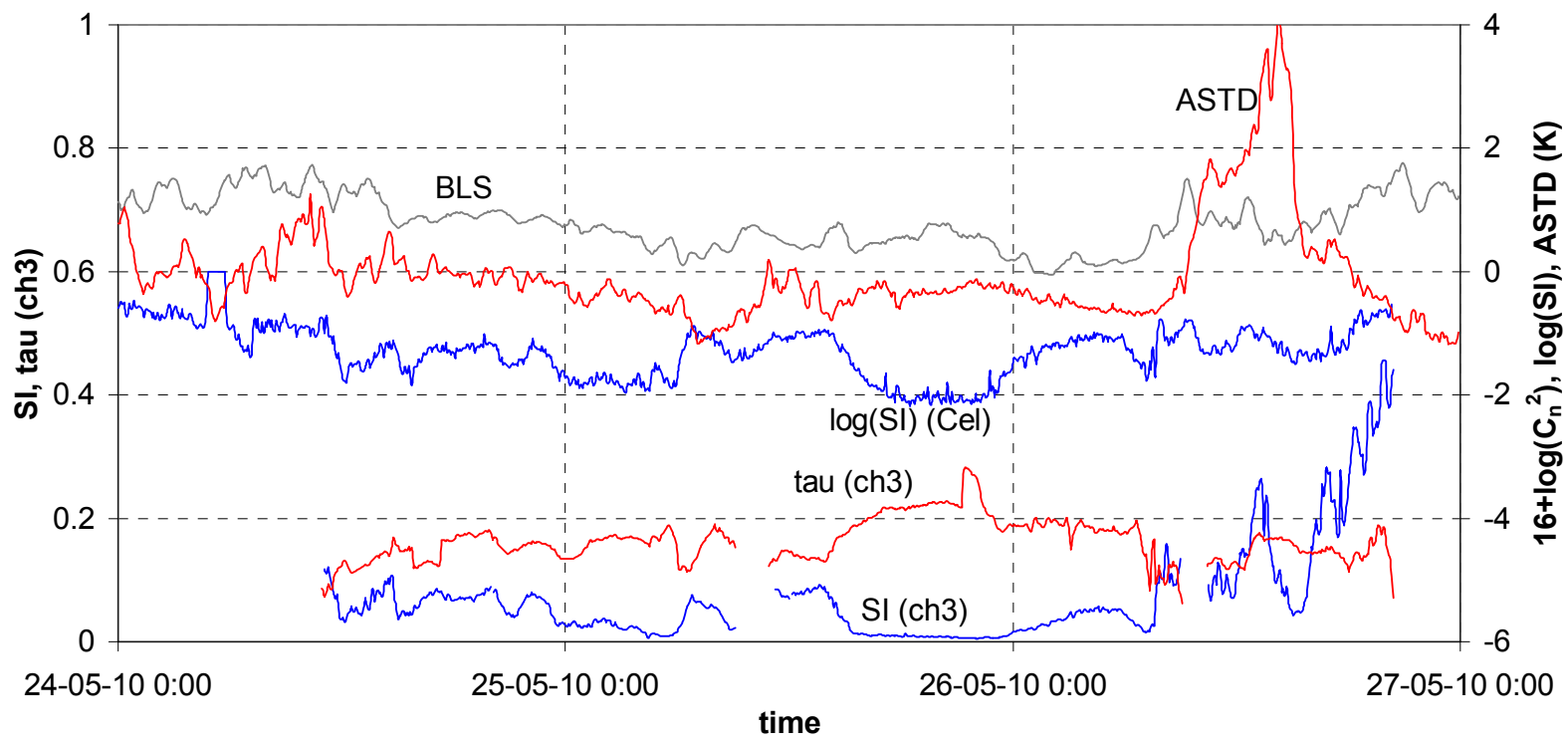

Figure 9. Three days of scintillation data (24-27 May), compared with $\mathrm{C}_{\mathrm{n}}{ }^{2}$ (BLS) and ASTD measurements 
the ASTD stays around zero and the $\mathrm{C}_{\mathrm{n}}^{2}$ decreases to somewhat above $10^{-16}$.In the periods of very low SI, as observed with both the MSRT and the Celestron on the $25^{\text {th }}$ of May, the $\mathrm{C}_{\mathrm{n}}{ }^{2}$ stays about the same. The high peak in ASTD on the $26^{\text {th }}$ however, does not provide significant increases in neither SI nor $\mathrm{C}_{\mathrm{n}}{ }^{2}$. Apparently the ASTD peak is occurring very local near Roman Rock and is not present in the rest of the measurement path.

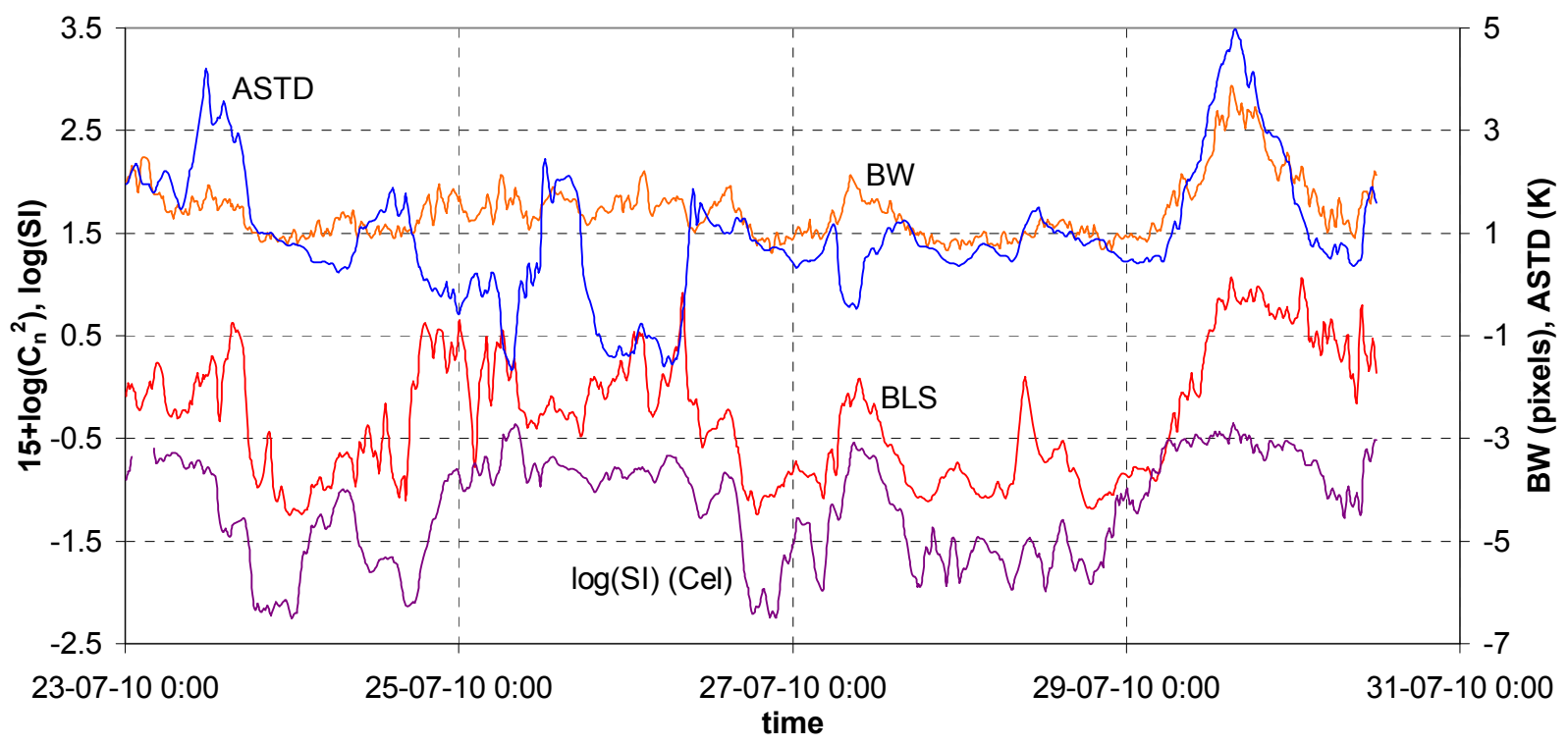

Figure 10. Comparison of scintillation, beam wander, ASTD and $C_{n}^{2}$ data for a period of eight days in July 2010.

The weather conditions in the second period (Figure 10) were generally more stable with SE winds, except on the $23^{\text {rd }}$ and $25^{\text {th }}$ of July, which can be seen from the jumps in the ASTD. These jumps are not accompanied by predictable behaviour of BLS and SI data. On the other hand, the temperature rise on the $29^{\text {th }}$ appears to be simultaneous with a rise in $\mathrm{C}_{\mathrm{n}}{ }^{2}$ and SI (more than a factor 10), while even the beam wander increases at the same time. Apparently the whole air mass between sources and receivers is homogeneous. Occasionally $\mathrm{C}_{\mathrm{n}}{ }^{2}$ values below $10^{-16}$ and SI values below 0.01 were recorded, for which no explanation could be found from the weather data. Scintillation data of the three MSRT channels, taken during both periods (except the morning sunglint hours) were compared. The result, shown in Figure 11 (left) makes clear, that the three SI's are linearly related and practically identical over more than two decades.
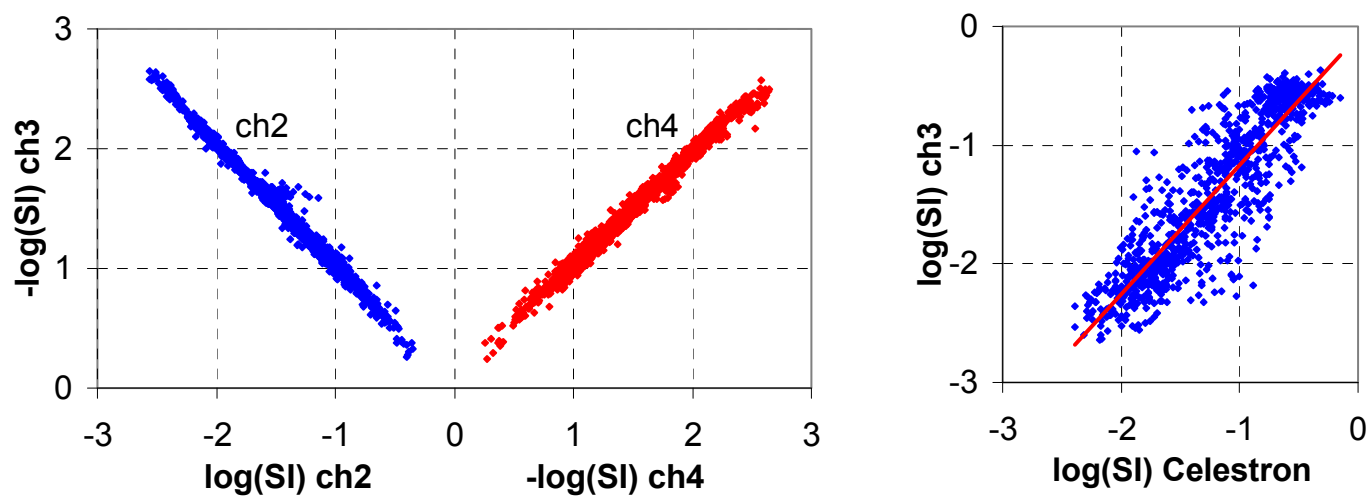

Figure 11. Comparison of SI's measured via different MSRT channels and Celestron

Apparently the scintillation index during the FATMOSE trial did not show any wavelength dependence, indicating that during the campaign, the nature of the scintillation was dominated by refraction effects. Diffraction from small eddies would create wavelength dependence. Hill [17] showed that in cases, where the diameter D is more than two times the 
Fresnel scale $(\lambda \mathrm{L})^{1 / 2}$, the wavelength dependence of scintillation disappears. Wang [16] derived an expression for $\sigma_{\chi}^{2}$ $\left(\mathrm{SI}_{\mathrm{R}}\right)$, showing this independence: $\sigma_{\chi}^{2}=\mathrm{CC}_{\mathrm{n}}{ }^{2} \mathrm{~L}^{3} \mathrm{D}^{-7 / 3}$, where $\mathrm{C}$ is a constant. Figure 11 (right) also shows a comparison between the SI values, measured by MSRT (channel 3, excluding sunglint events) and Celestron during the second period, including the trendline: $\log (\mathrm{SI})_{\mathrm{MSRT}}=1.089 \log (\mathrm{SI})_{\mathrm{Cel}}-0.0772$ with a correlation coefficient of 0.90 . Apparently the difference in receiver apertures does not create big differences in SI values.
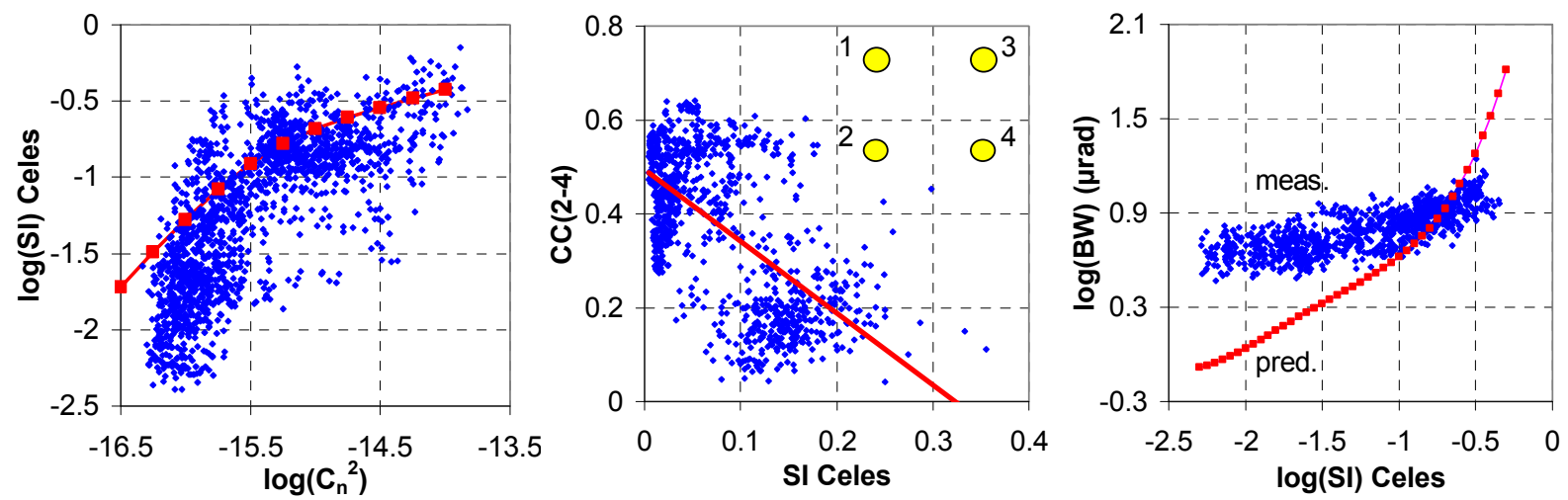

Figure 12. Comparison of SI (Celestron) and $\mathrm{C}_{\mathrm{n}}{ }^{2}$ (including predictions, left); the correlation coefficient of two MSRT channels (2-4) versus SI (centre) and Beam Wander (in $\mu \mathrm{rad}$ ) versus SI (right). All data are taken from the second period (23-31 July 2010). The front view of the MSRT pupils are shown (centre). The data are averaged over 20 minutes and sampled each 10 minutes

In Figure 12 (left), the SI data from the Celestron and the $\mathrm{C}_{\mathrm{n}}{ }^{2}$ data from the BLS scintillometer are compared, together with SI predictions $\left(\mathrm{SI}_{\mathrm{p}}\right.$ ) from the strong turbulence theory (aperture averaged): $\mathrm{SI}_{\mathrm{p}}=\mathrm{SI}_{\mathrm{R}} \mathrm{A}$. It is found, that for $\mathrm{C}_{n}{ }^{2}$ values above $2 * 10^{-16}$, the predictions and the measurements correspond relatively good. Below that level, the measured data become an order of magnitude smaller than the predicted data. This is probably due to the limited measurement range of the BLS scintillometer, not giving reliable data below $4 * 10^{-16}$ for a range of $2000 \mathrm{~m}$ ([13]). The $\mathrm{C}_{\mathrm{n}}{ }^{2}$ value, associated with an SI level of 0.01, should be approximately $1.5 * 10^{-17}$.

A different topic is the correlation of the signals of two neighbouring MSRT channels, of which an example is shown in Figure 12 (centre). Although the pupils of channels 2 and 4 are separated $11.5 \mathrm{~cm}$, the lightbeams, going from the $20 \mathrm{~cm}$ source towards the $4 \mathrm{~cm}$ receivers, overlap most of the path, so one might expect a large correlation during most of the time. This is not found, partly due to the transverse wind, delaying the passage of the eddies through the line of sight. But also in cases of low windspeed the correlation may be poor. In the example in Figure 12, a comparison is made between the correlation coefficient of channels 2 and 4: $\mathrm{CC}(2-4)$ and the SI of the Celestron, where a high correlation coefficient corresponds with a low SI value, while the SI increases with lower CC values. This qualitative result is just what may be expected due to turbulence. Rather frequently however, this correspondence is not found for unclear reasons.

From the comparison of the beam wander BW with the measured SI, shown in Figure 12 (right), it is observed that the variations in $\mathrm{BW}$ are limited to about a factor 4 over the range of two decades for the SI. The same figure also shows a prediction, based upon the relations (3) and (4) between $\mathrm{C}_{n}{ }^{2}$ and SI using the strong turbulence theory and the equation relating $\mathrm{BW}$ and $\mathrm{C}_{\mathrm{n}}^{2}[9]$ :

$$
\mathrm{BW}=\left(2.91 \mathrm{D}^{-1 / 3} \mathrm{C}_{\mathrm{n}}{ }^{2} \mathrm{~L}\right)^{0.5} \text {; with } \log \left(\mathrm{C}_{\mathrm{n}}{ }^{2}\right)=0.6623 \mathrm{x}^{4}+4.2334 \mathrm{x}^{3}+9.9979 \mathrm{x}^{2}+11.458 \mathrm{x}-10.623 ;\left(\mathrm{x}=\log (\mathrm{SI})=\log \left(\mathrm{SI}_{\mathrm{R}} \mathrm{A}\right)\right.
$$

The approximation for $\log \left(\mathrm{C}_{\mathrm{n}}^{2}\right)$ is accurate for $\mathrm{C}_{\mathrm{n}}^{2}$ values between $10^{-17}$ and $10^{-14}$. For $\mathrm{D}$ and $\mathrm{L}$, the values of $0.2 \mathrm{~m}$ and $15.7 \mathrm{~km}$ have been used again, delivering for $\mathrm{BW}: \log (\mathrm{BW})=8.447+0.5 \log \left(\mathrm{C}_{\mathrm{n}}{ }^{2}\right)$. The prediction for $\mathrm{BW}$ is apparently showing much greater variation than the measured one. It may be, that the $\mathrm{C}_{\mathrm{n}}{ }^{2}$ prediction from the strong turbulence theory via the measured SI, is incorrect, as the impact of turbulence on scintillation is different from that on beam wander. In a previous paper [4] it was shown that the relation between the measured $\mathrm{BW}_{\mathrm{m}}$ and the $\mathrm{BW}_{\mathrm{p}}$ predicted from the measured $\mathrm{C}_{\mathrm{n}}^{2}$ (BLS) data, was rather good: $\mathrm{BW}_{\mathrm{m}}=0.57 * \mathrm{BW}_{\mathrm{p}}+2.97$. In this case however, it was found just before, that the lower $\mathrm{C}_{\mathrm{n}}^{2}$ values are probably too high. 


\section{SELECTED DATA SERIES}

Until so far, data sequencies for a few consecutive days have been shown, most of them for SE wind directions under more or less stable weather conditions. In this section, a selection of data is presented, taken at various times during the FATMOSE campaign. For each of the 458 events, it was made sure, that the conditions did not change during a few hours before and after the sampling time. Care was taken that the selection is representative for the total FATMOSE period. In ref. [4], blur and $\mathrm{C}_{\mathrm{n}}{ }^{2}$ data have been shown for the same selection, while statistics for the complete data set are given in [1]. In Figure 13, the ASTD, windspeed (collected at Roman Rock) and $\log (\mathrm{SI})$ (the mean for the Celestron sources 1 and 2) are presented for the selected data series.

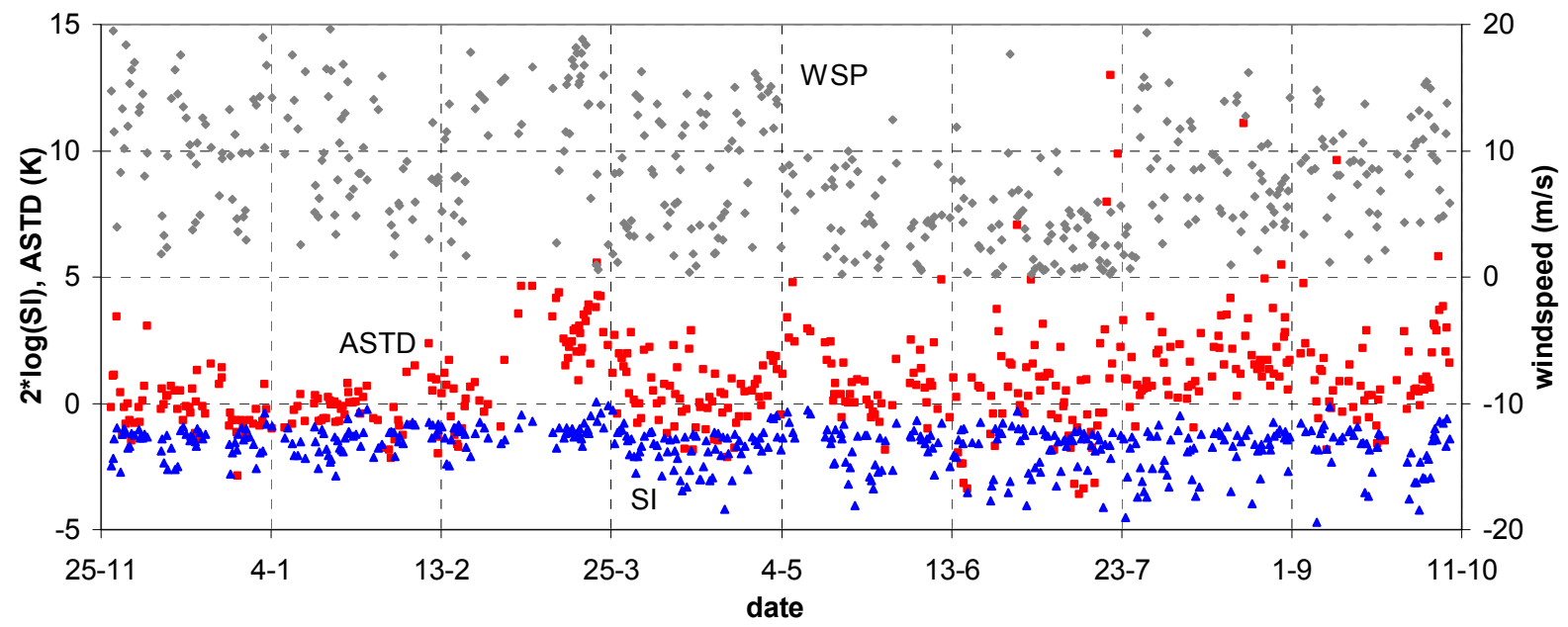

Figure 13. Selected data series (during the four seasons) with windspeed (diamonds), ASTD (squares) and SI (triangles).

The windspeed varies from 0 to $20 \mathrm{~m} / \mathrm{s}$ with about the same probability for each speed. It is noted, that windspeed data from Roman Rock and the weather station at IMT correspond quite good. The ASTD data are varying from -2.5 to $+8 \mathrm{~K}$, all scattered around $0 \mathrm{~K}$. As mentioned before, these data are locally measured, implying that due to variations in the water temperature in the Bay, the ASTD can momentarily vary a few degrees along the path. The SI data are ranging from 0.005 to 1 . Statistical properties of the selected data series, as they are of importance for system designers and modelers, are given for $\mathrm{C}_{\mathrm{n}}{ }^{2}$, SI and BW in Figure 14. A histogram of the year-round blur data has been presented in a previous paper [4], showing that $50 \%$ of the blur is greater than $20 \mu \mathrm{rad}$.
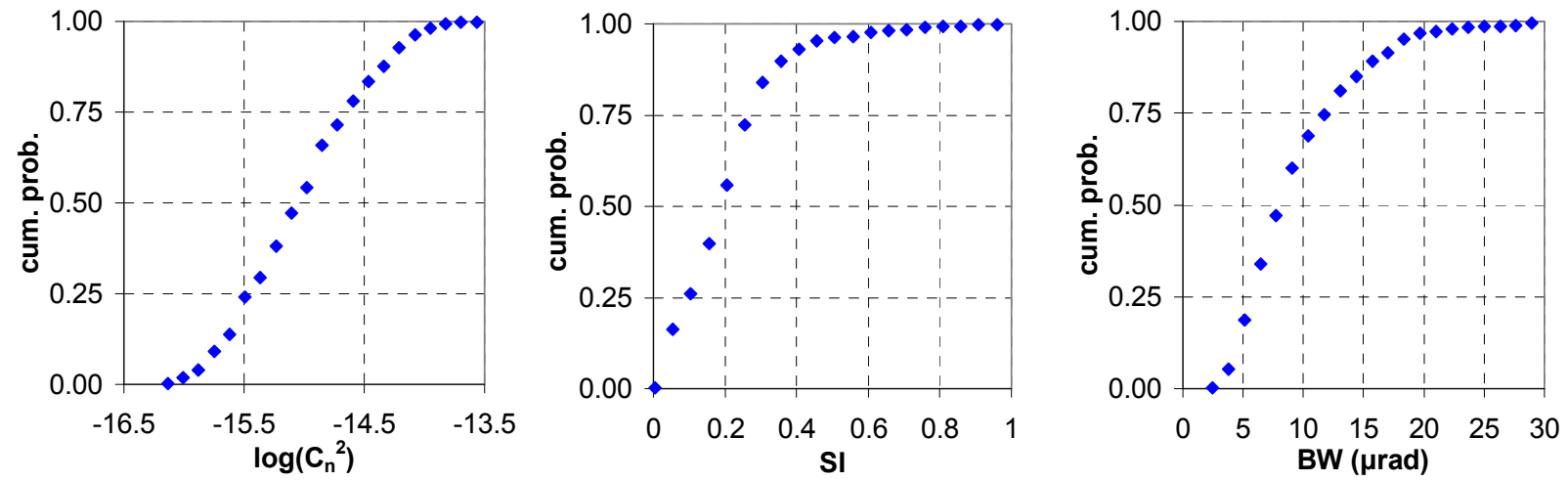

Figure 14. Histograms (cumulative probability) of $\mathrm{C}_{\mathrm{n}}^{2}$ (BLS), SI (Celestron) and BW for the selected data series

The $50 \%$ cumulative probability for the BLS data is shown to be $10^{-15} \mathrm{~m}^{-2 / 3}$, noting that this sensor probably has a lower limit of $10^{-16}$. The $50 \%$ level for SI is about 0.19 , which is a moderate level without saturation. The BW histogram shows a $50 \%$ level of about $8 \mu \mathrm{rad}$. 
The next issue concerns an investigation of the reliability of TARMOS calculations, based upon the weather data from Roman Rock, and their comparison with the $\mathrm{C}_{\mathrm{n}}{ }^{2}$ data from the BLS scintillometer. The TARMOS code, developed by Kunz [11] and implemented in the EOSTAR model [18] is using the bulk weather parameters: air- and sea temperature, relative humidity, windspeed and air pressure, governing the transport of heat, momentum and moisture in the lower boundary layer. Figure 15 (left) shows the comparison with virtually a small correlation. The mean $\mathrm{C}_{\mathrm{n}}^{2}$ values however, correspond quite good, being roughly $10^{-15}$. It is also found, that TARMOS predicts $\mathrm{C}_{\mathrm{n}}^{2}$ values below $10^{-16}$, even as low as $10^{-18}$ occasionally, which was never obtained with the BLS system.
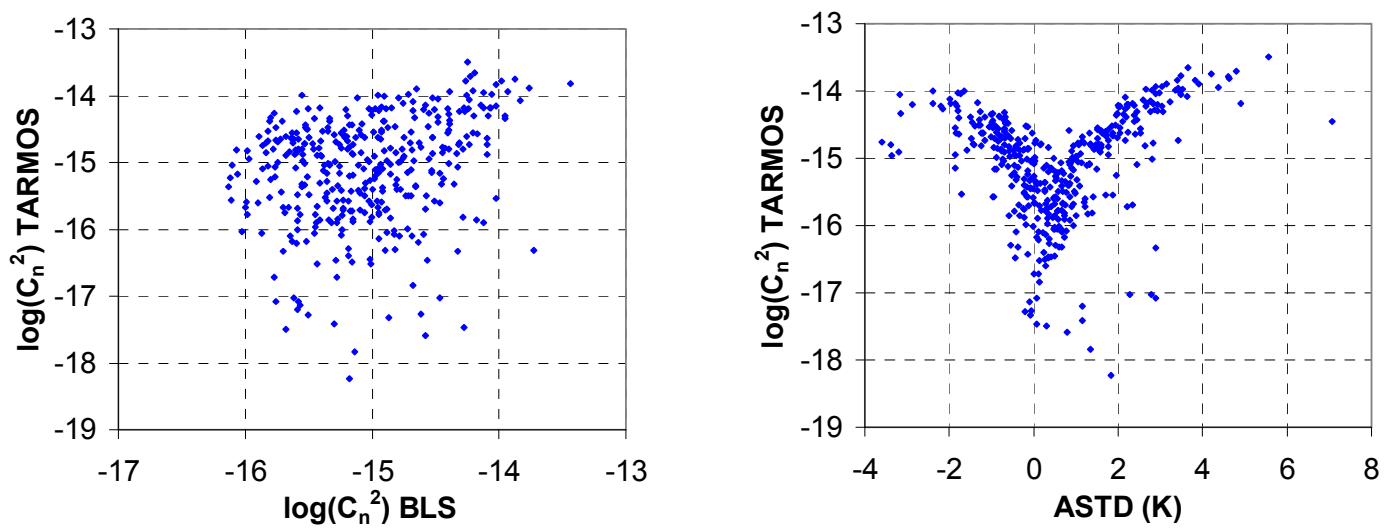

Figure 15. Comparison of predicted $C_{n}^{2}$ (TARMOS) and measured $C_{n}^{2}$ (BLS) and TARMOS prediction of $C_{n}^{2}$ for the ASTD values from the selected data series

These low values for $\mathrm{C}_{\mathrm{n}}^{2}$ predictions are following from the TARMOS level for ASTD values around $+0.5 \mathrm{~K}$, as was noted already in [3]. ASTD is the parameter of major importance in these calculations, which is illustrated in Figure 15 (right), where the weather data from the selected series is used as input. The dip in $\mathrm{C}_{\mathrm{n}}^{2}$ for ASTD's of $0.5 \mathrm{~K}$ is clearly visible, although a certain spread is found due to influences of relative humidity and windspeed. Similar to Figures 12 (left and right) SI (Celestron), $\mathrm{C}_{\mathrm{n}}{ }^{2}$ (BLS) and BW data from the selected data series are compared in Figure 16.
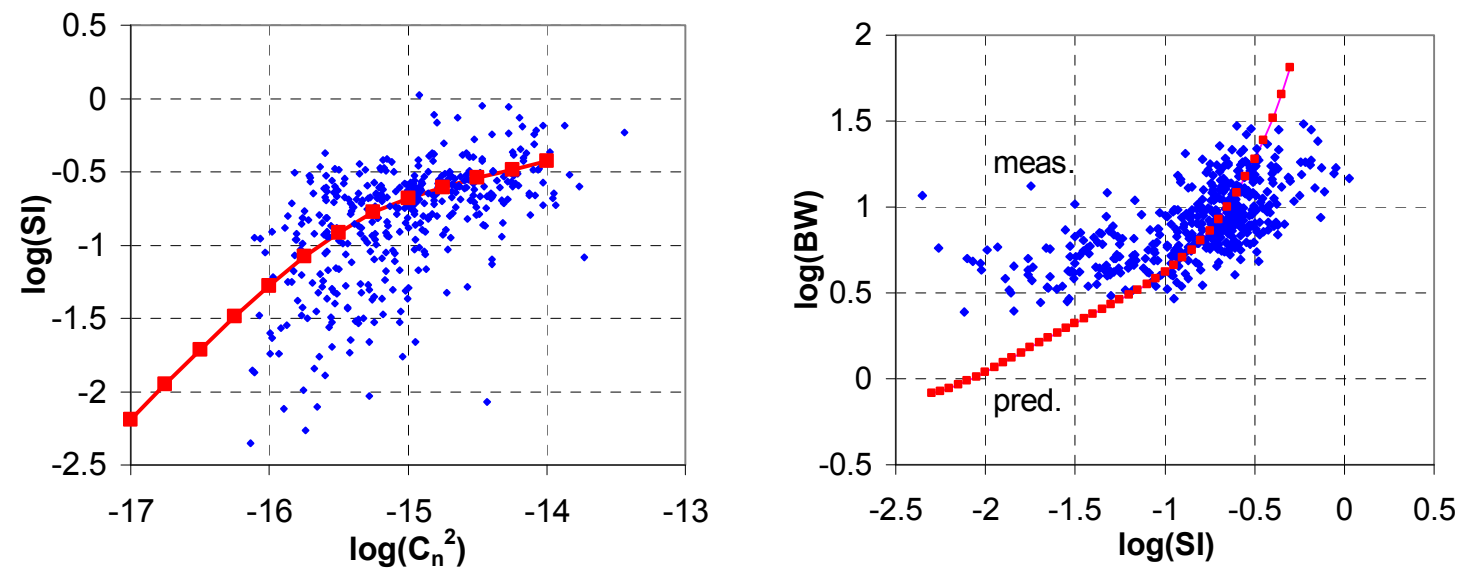

Figure 16. Comparison of measured $\mathrm{SI}$ and $\mathrm{C}_{\mathrm{n}}{ }^{2}$ and $\mathrm{C}_{\mathrm{n}}{ }^{2}$ predicted from SI with aperture averaging factor; $\mathrm{BW}$ (in $\mu \mathrm{rad}$ ) versus SI measured and BW, predicted from SI (via strong turbulence approximation) for selected data series

The relation between SI and $\mathrm{C}_{\mathrm{n}}{ }^{2}$ in Figure 16 (left) is similar to the results in Figure 12 (left) and are again somewhat limited for $\mathrm{C}_{\mathrm{n}}^{2}$ values below $10^{-16}$. Between $10^{-16}$ and $10^{-14}$ the correspondence between the measured and predicted $\mathrm{C}_{\mathrm{n}}^{2}$ is fairly good. The prediction of BW data from the SI data via the approximation (5) in section 6 corresponds better with the measured BW data in this selected data series than in the July series (Figure 16 right). It is found however that the prediction of $1 \mu \mathrm{rad}$ for an SI of 0.01 is never measured. The measured values are more of the order of $3 \mu \mathrm{rad}$. 


\section{DISCUSSION AND CONCLUSIONS}

In this paper the results are presented of year-round long-range scintillation measurements, carried out over coastal water in the False Bay (South Africa). The results of this experiment are of key importance for the prediction of electro-optical sensor performance. In order to better understand the results, a large number of additional equipment was installed, such as a local scintillometer (BLS), a sonic anemometer and a weather station for providing input data for the TARMOS code. These devices provide, each in its own way, values for the structure parameter for the refractive index: $\mathrm{C}_{\mathrm{n}}^{2}$. One of the issues for investigation was a comparison of these results, where it was noted from a previous paper [4], that the mean value of $\mathrm{C}_{\mathrm{n}}^{2}$ over the whole year was about $10^{-15} \mathrm{~m}^{-2 / 3}$. This value is an order of magnitude lower than for over land conditions, mainly due to the fact, that the prevailing wind direction is South-East (from the sea). The method to obtain $\mathrm{C}_{\mathrm{n}}{ }^{2}$ from the sonic data is described in this paper while the TARMOS method was described before [3]. In some cases (11 April 2010) the output of the three devices correspond very good, even in comparison to the long-range scintillation data, but in general the correspondence is rather poor. The BLS scintillometer, measuring over a $1.8 \mathrm{~km}$ path averages the turbulence effects, while the sonic and TARMOS output is based on real local data (at the Roman Rock Lighthouse). From the sonic data, histograms of the windspeed, wind directions and temperature fluctuations are presented, while temporal Fourier spectra are shown for a condition of high windspeed. The slope of the wind spectra corresponds well with the Kolmogorov theory (2/3 power law), assuming the validity of Taylor's hypothesis of frozen turbulence. The spectrum of the temperature fluctuations is flattening above a frequency of $1 \mathrm{~Hz}$, indicating that smaller eddies may have larger fluctuations.

These statistics has also been made up for the long-range $(15.7 \mathrm{~km})$ scintillometer, providing 200 samples per second. The histograms for low and high turbulence condition, show nicely the log-normal character of the signals in both cases. The Fourier spectra show the predicted (Kolmogorov) $-5 / 3$ fall off with frequency for frequencies above $10 \mathrm{~Hz}$, which should be, according to Kolmogorov $1 \mathrm{~Hz}$. The signals of the long-range scintillometers (actually the MSRT radiometer and the Celestron imager) are not saturated due to pupil averaging. Saturation may occur in scintillometers, working with point sources and detectors. Clifford [19] developed a theory describing the saturation phenomenon, occurring when the log-amplitude variance $\sigma_{\chi}^{2}>0.3$, the limit of weak turbulence theory. Together with Wang [16] he designed a saturationresistent scintillometer, based upon an extended aperture for the receiver. The limit of the weak turbulence, based upon the Rytov method, follows from the relation: $\mathrm{SI}_{R}=4 \sigma_{x}^{2}=1.23 \mathrm{C}_{\mathrm{n}}^{2}(2 \pi / \lambda)^{7 / 6} \mathrm{~L}^{11 / 6}$ (plane wave). From this relation it appears, that for the long-range (point source and receiver, plane wave) saturation occurs for a $\mathrm{C}_{\mathrm{n}}^{2}$ value of $1.8^{*} 10^{-16}$. For higher $\mathrm{C}_{\mathrm{n}}{ }^{2}$ values, the strong turbulence theory should be applied, especially when aperture averaging is incorporated, such as introduced by Churnside [20] and Andrews [15]. By using the formulae, given by the latter, aperture averaging factors A were calculated for various pupil diameters and $\mathrm{C}_{\mathrm{n}}{ }^{2}$ values. Next they were applied to the scintillation data for one week in July and a representative data set over the whole FATMOSE campaign, where SI data were compared with the BLS data, together with $\mathrm{C}_{\mathrm{n}}{ }^{2}$ data, calculated via the factor $\mathrm{A}$. It appeared that the measured and predicted $\mathrm{C}_{\mathrm{n}}{ }^{2}$ data above the level of $10^{-16}$ correpond quite good, but below $10^{-16}$ the BLS data are incorrect. The long-range scintillometers were able to measure $\mathrm{C}_{\mathrm{n}}^{2}$ values as low as $10^{-17}$, corresponding to SI levels of about 0.01 .

The measured SI data were also used (after conversion into $\mathrm{C}_{\mathrm{n}}{ }^{2}$ with the strong turbulence approach) to be compared with beam wander data from the Celestron imager. It appeared, that predicted and measured BW correspond quite good for higher SI values; for lower SI values (0.01), BW stays at a higher level of about a factor 3-5. A comparison of the SI values of the MSRT radiometer and the Celestron imager showed a very good correlation for all periods, and practically the same, except in morning hours, when sunglints disturbed the radiometer. This shows, that aperture averaging occurs on both sides, as the MSRT source and Celestron receiver have the same size $(20 \mathrm{~cm})$. Another comparison concerned the SI for the three wavelengths of the radiometer: 0.6, 0.9 and $1.5 \mu \mathrm{m}$ (being about equal). According to the weak turbulence theory (with point receiver), SI is about proportional to the inverse of the wavelength. Hill [17] and Wang [16] showed however, that this prediction is not valid when the diameter is more than twice the Fresnel scale: $(\lambda \mathrm{L})^{1 / 2}$. Another investigation concerned the correlation coefficient for the signal of two neighbouring MSRT channels, as this may contain information on the transverse coherence length. This correlation did appear only occasionally, but most of the time the result was negative. Histograms were presented for $\mathrm{C}_{\mathrm{n}}{ }^{2}$ (from BLS), SI (Celestron) and BW, taken from the representative data series, showing that the $50 \%$ cumulative probability levels were respectively: $10^{-15}, 0.19$ and $8 \mu \mathrm{rad}$. Finally a comparison was made between TARMOS $\mathrm{C}_{\mathrm{n}}{ }^{2}$ predictions and $\mathrm{C}_{\mathrm{n}}{ }^{2}$ data, measured with the BLS, showing that the mean values correspond quite good, except for ASTD values around $+0.5 \mathrm{~K}$. In this case, TARMOS predicts very low $\mathrm{C}_{\mathrm{n}}{ }^{2}$ values due to the lack of transport of heat in the lower boundary layer. It is concluded, that both long-range 
scintillometers have been succesfully applied during FATMOSE, while providing useful year-round $\mathrm{C}_{\mathrm{n}}^{2}$ data, even in the most frequently occurring conditions of strong turbulence. It was found, that the mean $\mathrm{C}_{n}^{2}$ value of $10^{-15}$ was an order of magnitude less that reported before for littoral conditions [21]. The lowest occurring $\mathrm{C}_{\mathrm{n}}^{2}$ value of $10^{-17}$, could only be measured with the long-range scintillometers. We want to thank Michael Saunders (Station 16 Commander) and Mario Fredericks (Station 16 Deputy Commander) from the National Sea Rescue Institute for permission for mounting the sources on the building in Strandfontein and their support during the trial. We further thank Peter Fritz, Leo Cohen and Koen Benoist of TNO for their support in preparing the hardware and software for the FATMOSE trial.

\section{REFERENCES}

[1] Arie N. de Jong et al, Preliminary results of the FATMOSE atmospheric propagation trials in the False Bay, South Africa, November 2009-July 2010, SPIE Volume 7828, Optics in Atmospheric Propagation and Adaptive Systems XIII, Toulouse, September 2010

[2] Arie N. de Jong et al, Application of year-round atmospheric transmission data, collected with the MSRT multiband transmissometer during the FATMOSE trial in the False Bay area, SPIE Volume 8161, Atmospheric Optics: Turbulence and Propagation, San Diego, August 2011

[3] Arie N. de Jong et al, Marine boundary layer investigations in the False Bay, supported by optical refraction and scintillation measurements, SPIE Volume 8178, Optics in Atmospheric Propagation and Adaptive Systems XIV, Prague, September 2011

[4] Arie N. de Jong et al, Long-term measurements of atmospheric point spread functions over littoral waters, as determined by atmospheric turbulence, SPIE Volume 8355, Infrared Imaging Systems: Design, Analysis, Modeling and Testing XXIII, Baltimore, April 2012

[5] Arie N. de Jong, Enhanced IR point target detection by atmospheric effects, SPIE Vol. 4820, Infrared Technology and Applications XXVIII, Seattle, July 2002

[6] Arie N. de Jong et al, TG16 point target detection experiment POLLEX, Livorno 2001, SPIE Volume 4820, Infrared Technology and Applications XXVIII, Seattle, July 2002

[7] Arie N. de Jong, Intensity variations of small airborne incoming targets, popping-up above the horizon, SPIE Vol. 5237, Optics in Atmospheric Propagation and Adaptive Systems VI, Barcelona, September 2003

[8] S. Pal Arya, Introduction to Micrometeorology, International Geophysics Series, Volume 79, Academic Press, 2001

[9] Robert R. Beland, Propagation through Atmospheric Optical Turbulence, The Infrared \& Electro-Optical Systems Handbook, Volume 2, SPIE Optical Engineering Press, 1993

[10] H. Demarcq et al, Climatology and variability of sea surface temperature and surface chlorophyll in the Benguela and Agulhas ecosystems as observed by satellite imagery, African Journal of Marine Science 25: 363-372, 2003

[11] Gerard J. Kunz, A bulk model to predict optical turbulence in the marine surface layer, TNO report FEL-96-A053, April 1996

[12] Arie N. de Jong et al, Measurement of optical refraction-, transmission- and turbulence effects in the False Bay, South Africa; June 2007; SPIE Volume 7108, Optics in Atmospheric Propagation and Adaptive Systems XI, Cardiff, September 2008

[13] Scintec AG, Scintec Boundary Layer Scintillometer Manual (revision 1.44), Tuebingen, November 2007

[14] Gill Instruments, Omnidirectional (R3) \& Asymmetric (R3A) Research Ultrasonic Anemometer User Manual, Lymington, Hampshire, October 2004

[15] Larry C. Andrews and Ronald L. Philips, Laser Beam Propagation through Random Media, $2^{\text {nd }}$ ed. , SPIE Press, Bellingham USA, 2005

[16] Ting-i Wang et al, A saturation-resistant optical scintillometer to measure $C_{n}^{2}$, JOSA Vol. 68, No. 3, March 1978

[17] R.J. Hill et al, Fine calibration of large-aperture optical scintillometers and an optical estimate of inner scale of turbulence, Applied Optics, Vol. 17, No. 22, November 1978

[18] A.M.J. van Eijk et al, EOSTAR Pro: a flexible extensive library to assess EO sensor performance, SPIE Volume 7828, Optics in Atmospheric Propagation and Adaptive Systems XIII, Toulouse, September 2010

[19] S.F. Clifford et al, Saturation of optical scintillation by strong turbulence, JOSA Vol. 64, No. 2, February 1974

[20] James H. Churnside, Aperture averaging of optical scintillations in the turbulent atmosphere, Appl. Opt. 30, No. 15 (1991)

[21] Karin R. Weiss-Wrana, Turbulence statistics in littoral area, SPIE Volume 6364, Optics in Atmospheric Propagation and Adaptive Systems IX, Stockholm, September 2006 